\title{
Analyzing the effect of urbanization on flood characteristics at catchment levels
}

\author{
X. Chen ${ }^{1}$, C. Tian ${ }^{1}$, X. Meng ${ }^{2}$, Q. Xu ${ }^{3,4}$, G. Cui ${ }^{1}$, Q. Zhang ${ }^{1}$, and L. Xiang ${ }^{1}$ \\ ${ }^{1}$ College of Hydrology and Water Resources, Hohai University, Nanjing, P. R. China \\ ${ }^{2}$ Zhejiang Institute of Hydraulics \& Estuary, Hangzhou, P. R. China \\ ${ }^{3}$ The State Key Laboratory of Hydrology-Water Resources and Hydraulic Engineering, Nanjing, P. R. China \\ ${ }^{4}$ Hydrology and Water Resources Department, NHRI, Nanjing, P. R. China \\ Correspondence to: X. Chen (chenxing@hhu.edu.cn)
}

Received: 11 March 2015 - Accepted: 11 March 2015 - Published: 11 June 2015

\begin{abstract}
It is increasingly recognized that the land-use change, especially urbanization has influenced hydrological attributes intensely. Flood characteristics variation could likewise increase flood risks and pose higher demand on water management. The paper aims to evaluate temporal and spatial processes of urbanization affecting flood events at catchment level. The study sites were Xiaoqinhe catchment and its sub-catchments, a part of lower Yellow river basin in northern China. Historic cities Jinan and Zibo in the area have experienced dramatic urban expansion in recent decades, about $5 \%$ growth of urban build-up area annually from 1990s to 2010s, and also pressed alarm for increasing flood disasters. In the paper, a HEC-HMS model was set up to simulate flood processes for different land-use scenarios. The possible effects of urbanization on flood characteristics were checked in study catchment and its sub-catchments.
\end{abstract}

\section{Introduction}

Urbanization levels reflect the degree of economic development of a region, but it also changes water cycle in many aspects. Urbanizing is a major land use/cover (LUCC) change trend for most regions of China in recent decades. It modifies hydrological process by affecting runoff generation and concentration which has been research focus currently (Amini et al., 2011; Delgado et al., 2009; O'Donnell et al., 2011; Wu et al., 2007).

Hydrological model supported by remote sensing technology and GIS has been widely applied in LUCC related studies. Under urban land enlargement scenario and identical precipitation, simulation of runoff variation can be analysed. Parameters in the model can be flexibly adjusted to reveal the mechanism of LUCC on runoff processes. Bronstert et al. (2007) stated that urban and farming changes decided the runoff responses based on simulation test of varied land cover conditions. Many researches (Arnold and Gibbons, 1996; White and Greer, 2006) concluded that storm runoff and peak flow increase with urban development as the proportion of impervious land increase. According to War- burtan et al. (2012) and Sanyal et al. (2014), spatial inhomogeneity of land use change makes local runoff responses present a more complex pattern. Fox et al. (2012) suggested channel management in urban areas has a counterbalance to reduce the runoff. Naef et al. (2002) studied the potential to reduce storm runoff by adjusting land uses in a mesoscale watershed.

China is in the process of rapid urbanization (Xu et al., 2010). A better understanding of land use change on hydrological responses is important for panning, management and sustainable development of the watershed. The objective of this study was to analyse the impacts of urbanization on flood characteristics in Xiaoqing catchment where undergoing intensive urban expansion during 1995-2008.

\section{Study catchment}

The sub-humid Xiaoqing catchment is located at the eastern end of the Yellow River basin in the province of Shandong, China, draining an area of $5451 \mathrm{~km}^{2}$ to the hydrologic station of Chahe (Fig. 1). Elevation ranges from $5 \mathrm{~m}$ in the northern 

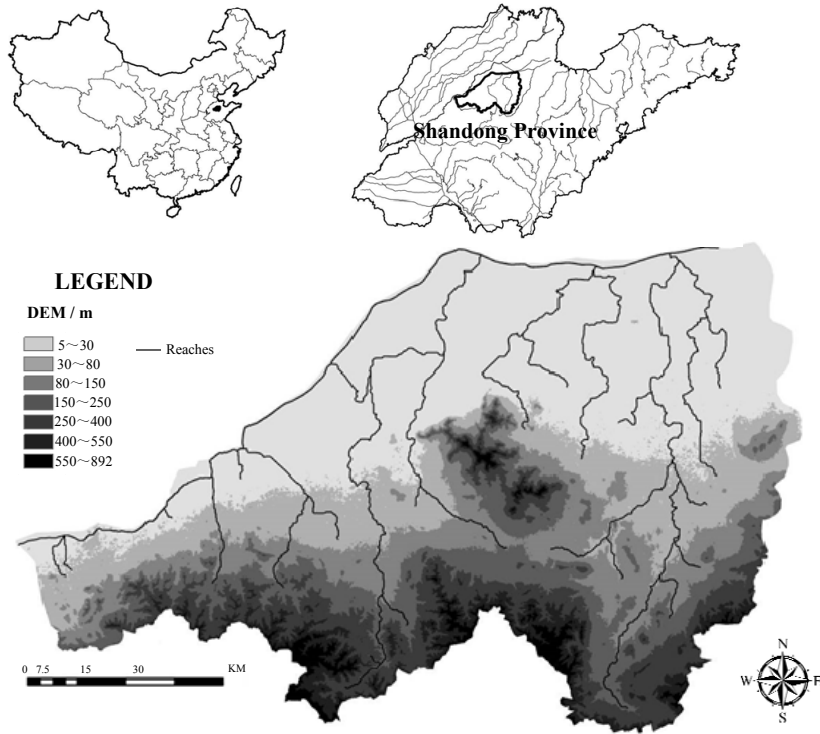

Figure 1. Location and DEM of the study catchment.

plain to $892 \mathrm{~m}$ in the southern mountain. Due to the terrain, parallel tributaries originated in the southern mountains flow into the Xiaoqing River at northernmost catchment eventually. The continental monsoon climate controls the area characterized by distinct four seasons with annual average temperature and rainfall of $12.9^{\circ}$ and $680 \mathrm{~mm}$ separately. Most rainfall events occur in summer (June-August), whose precipitation accounts for about $70 \%$ of the year amount. Soils through the catchment tend to be alkaline and belong to cinnamon, dark loessial and alluvial soil from south to north. Land cover is influenced by topography. The upland area maintains deciduous broad leaved forest. Central area of low hills covered largely by commercial forest. Agriculture vegetation mainly are wheat, corn, millet and potatoes.

The study area contains two megapolis of Jinan and Zibo, along with their satellite cities of Zhangqiu, Zouping and Huantai. These cities experienced rapid development and population expansion during 1990-2010. The mainstream in the area, Xiaoqing River, plays an important role in flood routing during storm events as it accepting flood flows from parallel upstream branches. It is also a key channel in SouthNorth Water Transfer Project. After two severe floods in 1996 and 2007, the government has increased capital investment in flood control projects. The Xiaoqing catchment implemented a series of measures as channel regulation, reservoir maintenance and flood detention preserving. Along the south side of Xiaoqing River, many lakes and ponds were reconstructed as detention basins. In November 1996, the upper reaches of the Xiaoqing River were widened from 35 to $60 \mathrm{~m}$ in rectangular section, and the river reaches near Chahe station were widened from 50 to $80 \mathrm{~m}$ in trapezoid section. The river section was expanded to $70-100 \mathrm{~m}$ in general after 2007.

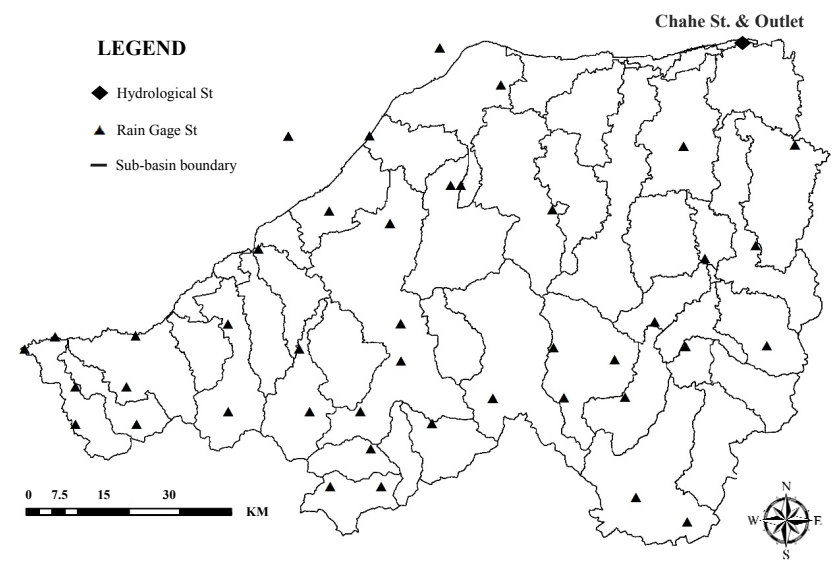

Figure 2. Sub-basins and rain gauge stations in the Xiaoqing catchment.

\section{Materials and methods}

\subsection{Hydrological model}

The Hydrologic Engineering Center's Hydrologic Modelling System (HEC-HMS) was chosen for simulating the rainfallrunoff process. It is a semi-distributed, event based model, which dividing the catchment into sub-basins, computing runoff response in each sub-basin, and routing the river flow to the outlet.

SCS curve number $(\mathrm{CN})$ method was adopted to calculate rainfall-runoff process. Empirical parameter $\mathrm{CN}$ can be easily accessed with land use data and soil classes, and amended by antecedent moisture conditions of soil. $\mathrm{CN}$ value could reflect the impact of land cover change on the runoff yield. Evapotranspiration losses were considered to be negligible in the storm event. The overland flow was simulated with Snyder Unit Hydrograph method. Channel flow was calculated with Muskingum routing method, and baseflow was determined by the exponential recession method. Detailed description of algorithms and parameters of the HEC-HMS model can be found in the HEC-HMS Technical Manual (USACE, 2000).

\subsection{Data preparation}

DEM of $30 \mathrm{~m}$ resolution was processed and used to generate stream network and define sub-basins. Because of human activities, extracted channels had a slight deviation with real ones which has been corrected artificially. The study catchment was divided into 49 sub-basins based on the spatial distribution of terrain, land cover, soil and rainfall gauge stations (Fig. 2). Hydrologic and terrain parameters were derived and calculated as model input. Soil types were converted into the hydrologic soil groups for the catchment. There are 45 rain gauge stations throughout the catchment, while the precipitation in each sub-basin was estimated by inverse distance interpolation method. Precipitation data of rainfall events were 
Table 1. Summary of model calibration and validation results for rainstorm events in Xiaoqing catchment.

\begin{tabular}{llccccrr}
\hline & Stage & Event & $\begin{array}{r}P \\
\mathrm{~mm}\end{array}$ & $\begin{array}{c}\text { Peak } Q_{\mathrm{obs}} \\
\mathrm{m}^{3} \mathrm{~s}^{-1}\end{array}$ & $\begin{array}{r}E \\
-\end{array}$ & $\begin{array}{r}D_{\mathrm{p}} \\
\%\end{array}$ & $\begin{array}{r}D_{\mathrm{v}} \\
\%\end{array}$ \\
\hline \multirow{2}{*}{1995 land cover } & Calibration & 800628 & 129 & 182 & 0.96 & -0.1 & -3.6 \\
& Calibration & 820616 & 44 & 165 & 0.89 & 1.4 & 6.0 \\
& Validation & 830803 & 113 & 133 & 0.81 & 6.4 & 12.8 \\
\hline \multirow{2}{*}{2008 land cover } & Calibration & 080717 & 93 & 148 & 0.97 & -2.4 & -2.6 \\
& Calibration & 070718 & 89 & 203 & 0.93 & 5.9 & 4.7 \\
& Validation & 060803 & 55 & 130 & 0.90 & -4.7 & -6.3 \\
\hline
\end{tabular}

recorded in $1 \mathrm{~h}$ time interval, the model simulations were also operated on $1 \mathrm{~h}$ step accordingly.

Analysing the urbanization development rates of the study area in different years, urban and residential areas gradually accelerated in the 1990s but appeared dramatically spreading over after year 2000. Besides, taking the integrity of aerial photographs and impact of cloud into account, two series of land cover data, i.e. 1995 and 2008, were selected and digitalized into $30 \mathrm{~m}$ resolution (Fig. 3). Since the study area is covered by two images, the colour difference of remote sensing images in different time phase may induce errors during interpreting process. So we interpreted images separately, and then mosaicking two vector graphs to generate land use maps for the study area. Based on the Chinese land resource classification system and regional land cover characteristics, the land use types in the Xiaoqing catchment was divided into build-up land, forest, farmland, grassland and waterbody.

\subsection{Model calibration and validation}

The HEC-HMS model was calibrated by two rain events and validated by one rain event for each given land use scenario. Because the hydrologic data set between 1985 and 2000 is not open and inaccessible, the dataset in early 1980s was used to verify the model under 1995 land use scenario. Examining images from 1980 to 1995 , the land use changed slightly, so it is considered to be reasonable. Three evaluation indexes were calculated to assess the model performance (Table 1) including the Nash-Sutcliffe coefficient of efficiency $(E)$, the deviation of peak discharge $\left(D_{\mathrm{p}}\right)$ and the deviation of runoff volumes $\left(D_{\mathrm{v}}\right)$.

$$
\begin{aligned}
& E=1.0-\sum_{i=1}^{N}\left(Q_{\mathrm{s} i}-Q_{\mathrm{o} i}\right)^{2} / \sum_{i=1}^{N}\left(Q_{\mathrm{o} i}-Q_{\mathrm{o}}\right)^{2} \\
& D_{\mathrm{p}}(\%)=\left(Q_{\mathrm{sp}}-Q_{\mathrm{op}}\right) / Q_{\mathrm{op}} \times 100 \\
& D_{\mathrm{v}}(\%)=\left(\sum_{i=1}^{N} Q_{\mathrm{s} i}-\sum_{i=1}^{N} Q_{\mathrm{o} i}\right) / \sum_{i=1}^{N} Q_{\mathrm{o} i} \times 100
\end{aligned}
$$

where $Q_{\mathrm{s} i}$ and $Q_{\mathrm{o} i}$ are the simulated and observed discharges at time step $i, \mathrm{~m}^{3} \mathrm{~s}^{-1} ; Q_{\mathrm{o}}$ is the mean observed discharge over simulation period, $\mathrm{m}^{3} \mathrm{~s}^{-1} ; Q_{\mathrm{sp}}$ and $Q_{\mathrm{op}}$ are the peak discharges over simulation period, $\mathrm{m}^{3} \mathrm{~s}^{-1}$.

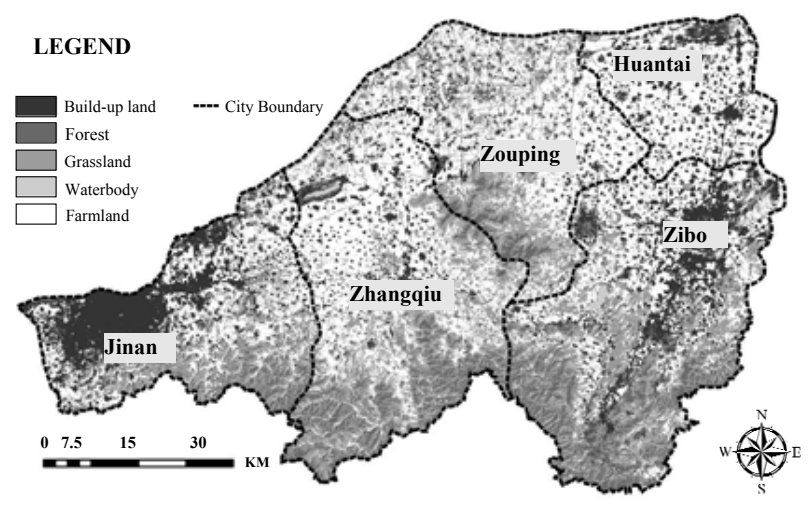

(a) 1995

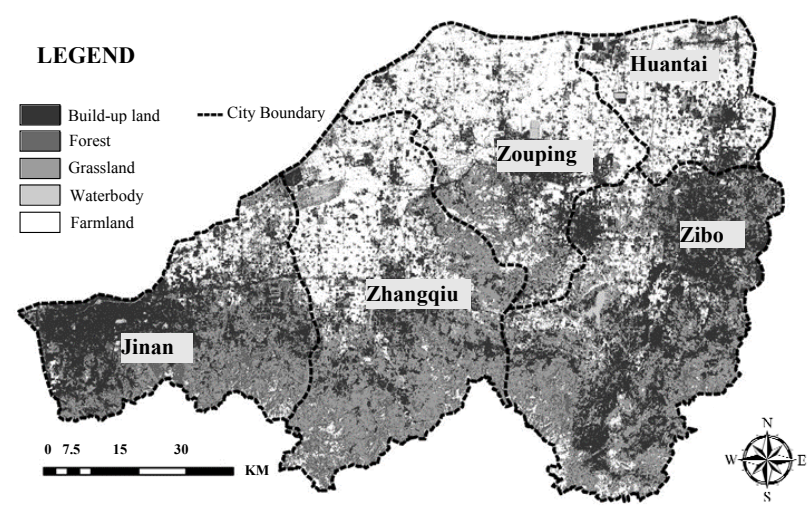

(b) 2008

Figure 3. Land cover maps of the study catchment in (a) 1995 and (b) 2008 .

Results of calibration and validation showed that the simulated flow compared well with observed values. The calibrated models were validated for flow prediction in the $\mathrm{Xi}$ aoqing catchment. 
Table 2. Percentage cover of different Land use for 1995 and 2008.

\begin{tabular}{lrrrrr}
\hline & Forest & Waterbody & Farmland & Build-up land & Grassland \\
\hline Percentage cover of 1995 & 8.8 & 0.8 & 43.3 & 19.1 & 28.0 \\
Percentage cover of 2008 & 15.8 & 1.2 & 27.8 & 40.5 & 14.6 \\
Difference of percentage cover (2008-1995) & 7.0 & 0.4 & -15.5 & 21.5 & -13.4 \\
\hline
\end{tabular}

\section{Results and discussion}

\subsection{Land cover changes}

In Fig. 3, the land use change was remarkable in Xiaoqing catchment during the period 1995-2008 (Fig. 3), especially in the central catchment, urban and residential area having a leap mainly due to burgeoning expansion of Zibo, Zhangqiu and Zouping. Land use change pattern reflects social and economic structure transform in the study catchment, and this changing pattern is typical in other regions of China from 1990 s to 2010s. Table 2 listed land use coverage percent for 1995 and 2008 land cover scenarios. Build-up area increased substantially from $19.1 \%$ in 1995 to $40.5 \%$ in 2008 . Meanwhile forest and waterbody areas enhanced by 7.0 and 0.4 percentage points respectively. That said, urbanization not only increases impervious area also makes decision makers pay more attention on flood control measures in the catchment which is beneficial to improve water storage capacity and flow drainage capacity. Correspondingly, farmland and grassland areas declined a lot, their coverages falling from 43.3 and $28.0 \%$ in 1995 to 27.8 and $14.6 \%$ in 2008 .

\subsection{Impact of land cover changes on runoff}

Rainfall event in 3 August 2006 was selected to analyse the effect of LUCC on runoff response in the Xiaoqing catchment. The average precipitation of the event is $55 \mathrm{~mm}$. Rainstorm centre located in the northern and western part of the basin, and the maximum rainfall is up to $103 \mathrm{~mm}$. Runoff responses to the storm event were simulated under 1995 and 2008 land covers (Fig. 4). The peak discharge was $130 \mathrm{~m}^{3} \mathrm{~s}^{-1}$ occurring on 5 August at 13:00 LT for the 2008 scenario, while the peak discharge decreased to $117 \mathrm{~m}^{3} \mathrm{~s}^{-1}$ and the time of the peak was $5 \mathrm{~h}$ ahead in 1995 scenario. Land cover change between 1995 and 2008 has produced $11.1 \%$ of peak discharge increment and $15.3 \%$ of excessive flood volume. Different with studies that suggested urbanization could forward the peak time (Chen et al., 2009; Ali et al., 2011; Sanyal et al., 2014), according to the simulation results, the peak time under 2008 land cover appeared later than that under 1995 land cover in the catchment. This also implied that the impact of urbanization on runoff have regional limitations, and researches in different watersheds may yield different results (Fox et al., 2012; Warburton et al., 2012). For the Xiaoqing catchment, effect of channel maintenance cannot be neglected which has been a routine practice since

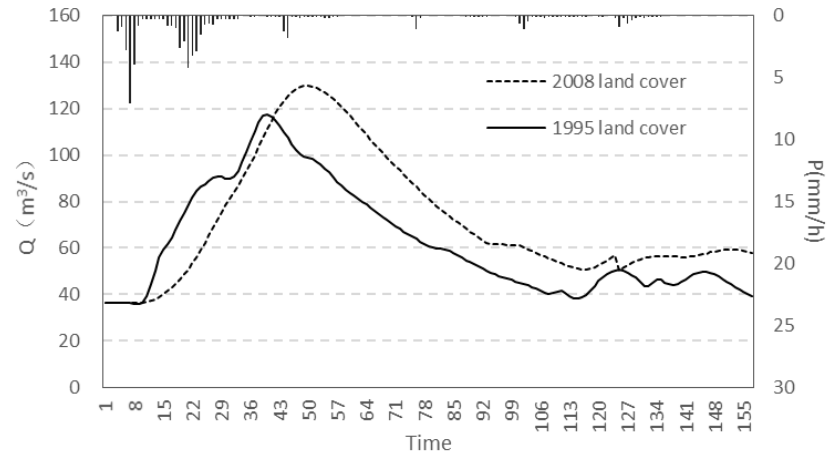

Figure 4. Simulated discharge hydrographs under 1995 and 2008 land cover for storm event No. 060803.

late 1990s, including bank stabilization, channel widening and desilting. Ecological engineering techniques were applied in river management gradually after 2005. Lakes and wetlands were restored and reconstructed. As a result, land cover changes in Xiaoqing catchment led to enlarged peak flow but delayed convergence time in storm events. Simulations on the other two events (830803 and 070718) showed the same pattern. The peak discharges increased 16.7 and $23.1 \%$, while the peak time delayed $5 \mathrm{~h}$ and $6 \mathrm{~h}$ respectively under 1995 and 2008 land cover.

Development of urbanization is heterogeneous over the whole catchment. Other factors or land use changes could counterbalance the consequences of impervious area increasing. Scale effect is another critical factor because impact of LUCC on flow may decrease with size of study area (Blöschl et al., 2007). Therefore, it is necessary to examine influences of land cover change on streamflow at sub-basin scale. Figure 5 showed spatial distribution of urbanization developing degree and simulated runoff depth change rate in each subbasin. Equations and variable meanings in Fig. 5 are as follows.

$$
\begin{aligned}
& P_{\mathrm{A}}=\frac{A_{\mathrm{b} 1}-A_{\mathrm{b} 2}}{A} \times 100 \\
& P_{\mathrm{R}}=\frac{R_{1}-R_{2}}{R_{2}} \times 100 \\
& R=\frac{W}{1000 \times A}
\end{aligned}
$$

where $P_{\mathrm{A}}$ is the percentage change of build-up land area, $\% ; A_{\mathrm{b} 1}$ and $A_{\mathrm{b} 2}$ are build-up area under 2008 and 1995 scenario, $\mathrm{km}^{2} ; A$ is the catchment area, $\mathrm{km}^{2} ; P_{\mathrm{R}}$ is the percent- 

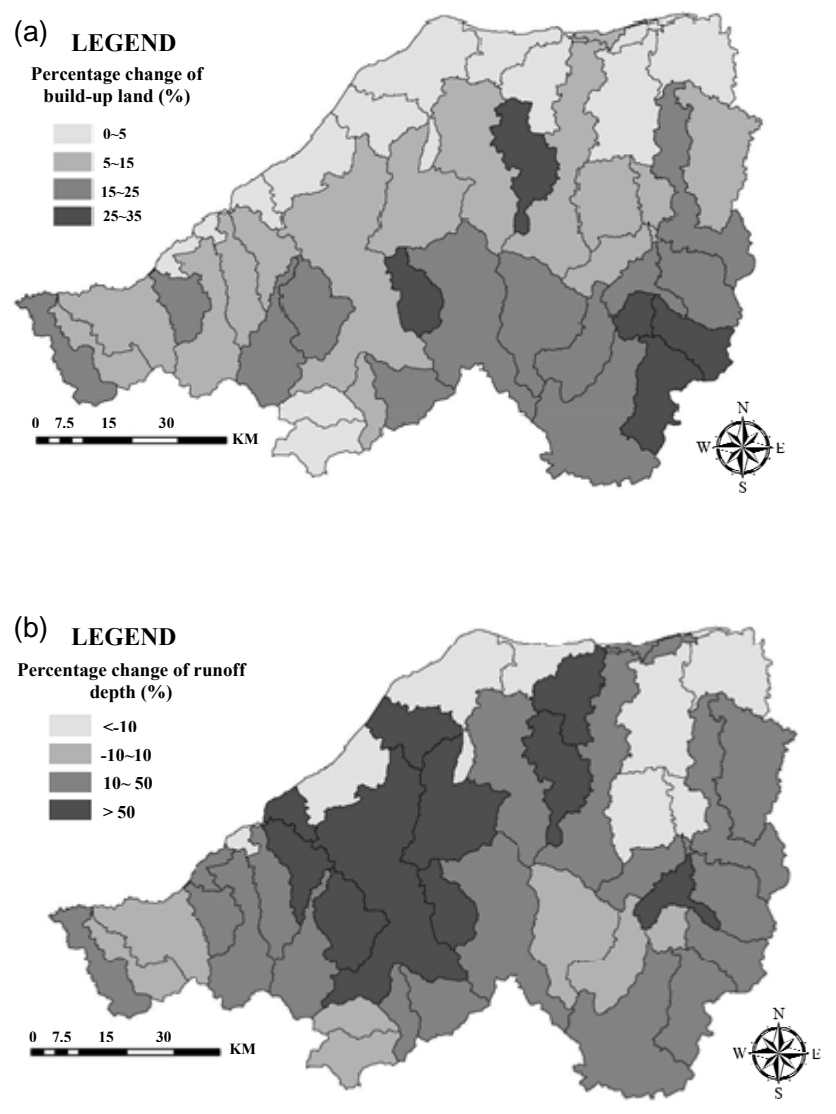

Figure 5. Percentage change of (a) build-up land proportion and (b) runoff depth at the sub-basin scale in 2008 scenario relative to 1995 scenario.

age change of runoff depth, $\% ; R_{1}$ and $R_{2}$ are the simulated runoff depth under 2008 and 1995 scenario, $\mathrm{mm} ; W$ is the total runoff volume during simulation period, $\mathrm{m}^{3}$.

As illustrated by Fig. 5, 72\% of the watershed area experiencing more than $5 \%$ of build-up area percentage increase. There are 38 and $8 \%$ area mainly located in central and southeast watershed which have more than 15 and $25 \%$ of build-up area percentage increase. Distribution of runoff depth change rate showed higher spatial variability. In Fig. 5b, negative values indicate that the $R$ value was lower in 2008 than 1995, and positive values show the opposite. Comparing Fig. 5a and Fig. 5b, certain correlation between spatial variations of urbanization and rainfall depth can be found, and urbanizing extent controlled runoff depth change more or less. Build-up area with percentage growth more than $5 \%$ was generally coincide with areas where runoff depth increased more than $10 \%$. However, urban area increase did not necessarily produce more runoff and some sub-basins present marked deviation from this positive trend. 5 sub-basins had slower development $\left(P_{\mathrm{A}}<5 \%\right)$ but produced substantial runoff increase $\left(P_{\mathrm{R}}>10 \%\right)$. 7 sub-basins had quicker development $\left(P_{\mathrm{A}}>5 \%\right)$ but the runoff basically kept unchanged $\left(P_{\mathrm{R}}<10 \%\right)$. It indicates that runoff generation is influenced by multiple factors such as land use, soil, terrain and meteorological conditions etc. Simulations on different rain storms may produce different responses (Pattison and Lane, 2012). Further simulations should be carried out to identify the major factor that influence the runoff response and to evaluate the degree of land use change on runoff in catchment and sub-basin scale. In addition, uncertainty and scale effect should be addressed in the further study. In this paper, the model only calibrated and validated by the streamflow data at the catchment outlet. Detailed data need to be collected and used to test simulations at sub-basin scale.

\section{Conclusions}

This study adopted an event-based hydrological model (HEC-HMS) to investigate the impacts of land use change on runoff responses in Xiaoqing catchment. The study area went through rapid urbanizing expansion between 1995 and 2008 . Meanwhile, city expansion also promoted flood proof activities as channel widening, detention basin construction and reservoir maintenance. The overall results of these changes on runoff were increased peak discharge and flood volume but lagged peak time at the catchment outlet. The relationship between urban development and hydrologic responses are complex at sub-basin scale. In general, more runoff was generated in the area with higher increase rate of build-up area, but increase magnitude of runoff did not present as simple linear relationship with the urban area expansion rate. Some sub-basins also showed opposite effect of urbanization on runoff. The findings in the paper provide useful information on effect of urbanization on flood characteristics and be helpful for decision makers to scientifically develop land use planning in the study catchment.

Acknowledgements. This study has been supported in part by the Natural Science Foundation of China (Grant No. 51209071, 51109137 and 51309078). Authors would like to thank S. Lin and K. Long for hydrologic data checking. Constructive comments by reviewer helped to improve the manuscript.

\section{References}

Ali, M., Khan, S. J., Aslam, I., and Khan, Z.: Simulation of the impacts of land-use change on surface runoff of Lai Nullah Basin in Islamabad, Pakistan Landsc. Urban Plan., 102, 271-279, 2011.

Amini, A., Ali, T., Ghazali, A., Aziz, A., and Akib, S.: Impacts of land-use change on streamflows in the Damansara Watershed, Malaysia, Arab. J. Sci. Eng., 36, 713-720, 2011.

Arnold, C. L. and Gibbons, C. J.: Impervious surface Coverage: The Emergence of a key environmental Indicator, J. Am. Plan. Assoc., 62, 243-258, 1996. 
Blöschl, G., Ardoin-Bardin, S., Bonell, M., Dorniger, M., Goodrich, D., Gutknecht, D., Matamoros, D., Merz, B., Shand, P., and Szolgay, J.: At what scale do climate variability and land cover change impact on flooding and low flows?, Hydrol. Process., 21, 1241-1247, 2007.

Bronstert, A., Bardossy, A., Bismuth, C., Buiteveld, H., Disse, M., Engel, H., Fritsch, U., Hundecha, Y., Lammersen, R., Niehoff, D., and Ritter, N.: Multi-scale modeling of land-use change and river training effects on floods in the Rhine basin, River Res. Appl., 23, 1102-1125, 2007.

Chen, Y., Xu, Y., and Yin, Y.: Impacts of land use change scenarios on storm-runoff generation in Xitiaoxi basin, China, Quant. Int., 208, 121-128, 2009.

Delgado, J., Llorens, P., Nord, G., Calder, I. R., and Gallart, F.: Modelling the Hydrological Response of a Mediterranean medium-sized headwater basin subject to land cover change: the Cardener River Basin (NE Spain), J. Hydrol., 383, 125-134, 2009.

Fox, D. M., Witz, E., Blanc, V., Soulie, C., and Penalver-Navarro, M.: A case study of land cover change (1950-2003) and runoff in a Mediterranean catchment, Appl. Geogr., 32, 810-821, 2012.

Naef, F., Scherrer, S., and Weiler, M.: A process based assessment of the potential to reduce flood runoff by landuse change, J. Hydrol., 267, 74-79, 2002.
O’Donnell, G., Ewen, J., and O'Connell, P. E.: Sensitivity maps for impacts of land management on an extreme flood in the Hodder catchment, UK, Phys. Chem. Earth, 36, 630-637, 2011.

Pattison, I. and Lane, S. N.: The link between land-use management and fluvial flood risk: a chaotic conception?, Prog. Phys. Geogr., 36, 72-92, 2012.

Sanyal, J., Densmore, A. L., and Carbonneau, P.: Analysing the effect of land-use/cover changes a sub-catchment levels on downstream flood peaks: A semi-distributed modelling approach with sparse data, Catena, 118, 28-40, 2014.

USACE - United States Army Corps of Engineers: Hydrologic Modeling System HEC-HMS: Technical Reference Manual, Washington, D.C., 2000.

Warburton, M. L., Schulze, R. E., and Jewitt, G. P. W.: Hydrological impacts of land use change in three diverse South African catchments, J. Hydrol., 414-415, 118-135, 2012.

White, M. D. and Greer, K. A.: The effects of watershed urbanization on the stream hydrology and riparian vegetation of Los Peñasquitos Creek, California, Land. Urb. Plan., 74, 125-138, 2006.

Wu, W., Hall, C. A. S., and Scatena, F. N.: Modelling the impact of recent land-cover changes on the stream flows in northeastern Puerto Rico, Hydrol. Process., 21, 2944-2956, 2007.

$\mathrm{Xu}, \mathrm{G} ., \mathrm{Xu}, \mathrm{Y}$., and $\mathrm{Xu}, \mathrm{H} .:$ Advance in hydrologic process response to urbanization, J. Nat. Resour., 25, 2171-2178, 2010. 